\title{
Emotional intelligence and personal growth initiative effects on subjective happiness among University students
}

\author{
Nuworza Kugbey ${ }^{1,2}$,* \\ Email: nkugbey@gmail.com \\ (http://orcid org/0000-0002-0413-0350) \\ Ethel Akpene Atefoe ${ }^{3}$ \\ Email: eatefoe@gmail.com \\ (http://orcid org/0000-0002-3801-3339) \\ Nkansah Anakwah ${ }^{4,5}$ \\ Email: nkansah.anakwah@maastrichtuniversity.nl \\ Kingsley Nyarko ${ }^{6,7}$ \\ Email: kingpong73@yahoo.com \\ Samuel Atindanbila ${ }^{7}$ \\ atindanbila@gmail.com
}

${ }^{1}$ Department of Family and Community Health, School of Public Health, University of Health and Allied Sciences, Hohoe Campus-Volta Region, Ghana

${ }^{2}$ Discipline of Psychology, School of Applied Human Sciences, University of KwaZulu-Natal, South Africa

${ }^{3}$ Department of Psychological Medicine and Mental Health, School of Medicine, University of Health and Allied Sciences, Ho-Volta Region, Ghana

${ }^{4}$ Department of Criminal Law and Criminology, Maastricht University, Maastricht, The Netherlands

${ }^{5}$ Department of Psychology, University of Portsmouth, Portsmouth, UK

${ }^{6}$ Department of Teacher Education, University of Ghana, Legon

${ }^{7}$ Department of Psychology, University of Ghana, Legon

Corresponding author: Nuworza Kugbey ${ }^{1,2}$,*

Email: nkugbey@gmail.com

Abstract 


\section{Abstract}

This study examined emotional intelligence and personal growth initiative influences on the level of subjective happiness among university students in Ghana. A total of 260 undergraduate students were participants (female $=69.8 \%$, mean age $=21.72, \mathrm{SD}=3.61$ Years). They responded to measures of emotional intelligence, personal growth initiative and subjective happiness. Results following hierarchical regression analysis indicate emotional intelligence and intentional behaviour domain of personal growth to predict students' level of subjective happiness after controlling for their demographic characteristics. These findings suggest that students' ability to manage and utilize their emotions as well as their personal growth initiative contribute significantly to their level of happiness.

Keywords: Emotional intelligence, personal growth initiative, subjective happiness, Ghana 


\section{INTRODUCTION}

Emotions and their expression carry personal significance in helping in adaptive functioning (Garland et al., 2010). Positive emotions exert buffering effects in the face of stressors arising from life challenges. Negative emotions may have dysfunctional consequences for important life outcomes (Garland et al., 2010). Emotional intelligence or the effective use of emotional abilities may help increase sense of well-being and general health (Zeidner, Matthews, \& Roberts, 2012). Emotional intelligence has also been linked with adaptive coping with stress (Salovey \& Mayer, 1990; Salovey, Rothman, Detweiler, \& Steward, 2000) and resilience (Schneider, Lyons, \& Khazon, 2013). High emotional intelligence is associated subjective wellbeing (Bar-On, 2005; Gallagher \& Vella-Brodrick, 2008; Martins, Ramalho, \& Morin, 2010).

Subjective wellbeing refers to a state that emerges from a feeling of satisfaction with one's physical health and oneself as a person, with one's close interpersonal relationships, and with one's occupation and financial situation (Bar-On, 2005). Subjective wellbeing is defined by both happiness (which reflects the affective component of wellbeing) and life satisfaction (which reflects the cognitive component of wellbeing) (Diener, Suh, \& Lucas, 1999; Ngamaba, 2016), although less stable than life satisfaction (Calys-Tagoe et al., 2014; George, 2009). Relatively little is known about predictors of subjective happiness in African settings. Most of the related studies have examined the predictors of subjective well-being (Addai, Opoku-Agyeman, \& Amanfu, 2014; Guse, Vescovelli, \& Croxford, 2017; Rugira, Nienaber, \& Wissing, 2013) rather than subjective happiness. Moreover, the ways in which personal growth initiative may augment subjective happiness has not been studied in African settings. We aimed to address this gap in the literature by examining the predictive ability of emotional intelligence and personal growth initiative on subjective happiness among college students in the developing country of Ghana. 


\section{Subjective happiness and subjective wellbeing}

Subjective happiness refers to an individual's affective evaluation of life characterized by fulfilment (Lyubomirsky \& Lepper, 1999). Subjective wellbeing can be differentiated from subjective happiness in that, whereas subjective happiness refers to only the emotional and affective aspects of individuals' evaluations of their lives, subjective wellbeing includes both the affective and cognitive components (Bar-On, 2005; Lyubomirsky \& Lepper, 1999). However, it is not uncommon to find these two concepts of subjective happiness and subjective wellbeing used interchangeably in the positive psychology literature (Bar-On, 2005; Ngamaba, 2016).

\section{Emotional intelligence and subjective happiness}

High emotional intelligence is related to sense of subjective happiness (Furnham \& Petrides, 2003; Ye, Yeung, Liu, \& Rochelle, 2018). This might be explained by the fact that emotional intelligence has an element of self-identity and happiness and a potential determinant of subjective happiness. Since subjective happiness is one's personal perception about his or her state of happiness (Lyubomirsky \& Lepper, 1999), it may be less surprising that people possessing high emotional intelligence also report greater subjective happiness, subjective well-being and life-satisfaction (Geng, 2016; Larsen, 2000; Ruiz-Aranda, Extremera, \& Pineda-Galán, 2014). Students with high levels of subjective happiness also might have a superior sense of personal growth initiative (Peltzer \& Pengpid, 2017; Peltzer, Pengpid, Sodi, \& Mantilla Toloza, 2017).

Personal growth initiative is a set of skills required for the intentional involvement in self-change and development (Robitschek, 1998). Individuals who possess high levels of personal growth initiative may have subjective wellbeing from embracing change (Robitschek \& Cook, 1999; Robitschek \& Keyes, 2009), which also might contribute to their overall sense of happiness (Neff, 
Rude, \& Kirkpatrick, 2007; Shorey, Little, Snyder, Kluck, \& Robitschek, 2007; Stevic \& Ward, 2008). However, what makes for happiness may vary by socio-cultural context, and findings of happiness studies from Western country settings cannot be assumed to generalize to African culture settings without further study.

\section{Correlates of Happiness in the Ghanaian setting}

In African culture settings, personal happiness is nested in interpersonal relationships or the interdependency of the self with the community (Ugwuanyi, 2014). Meaningful sense of community belongingness and positive social relationships are important to social wellbeing in African culture heritage communities (Mpofu, 2011). This is in part because individual sense of social worth is tied to contributing to the common social good (Ugwuanyi, 2014). The ability to manage social relationships and to engage in intentional actions targeted at improving one's sense of well-being is thus very essential to the happiness Ghanaians (Osei-Tutu, Dzokoto, Hanke, Adams, \& Belgrave, 2018).

Ghanaians generally perceive themselves as happy or , easy-going (Addai et al., 2014; Addai, Opoku-Agyeman, \& Amanfu, 2015). Ghanaians with both material and social capital are happier than others (Addai et al., 2014; Sulemana, 2015) and from the familial social reciprocity they enjoy (Tsai \& Dzorgbo, 2012). Happiness among Ghanaians context goes beyond just an affective state to include economic and social well-being of the individual. Consequently, to fully understand happiness from the Ghanaian perspective, both affective and behavioral determinants need to be considered. 


\section{Aim of current study}

This study sought to examine whether emotional intelligence and personal growth initiative have any significant effects on students' subjective happiness after controlling for their demographic characteristics. The primary research question was: To what extent do emotional intelligence and personal growth explain subjective happiness among Ghanaian college students?

\section{METHODS}

\section{Participants and setting}

A convenience sample of 260 undergraduate students attending a public university in Ghana were participants $($ females $=69.8 \%$, mean $=21.72$ years, $\mathrm{SD}=3.61$ years; $40 \%$ freshman). About $96 \%$ of the students were unmarried. Most of the participants belong to the Christian religion (93.3\%) whilst the remaining $6.7 \%$ were non-Christians.

\section{Measures}

The students completed the Trait Emotional Intelligence Questionnaire - Short Form (TEIQueSF) (Petrides \& Furnham, 2006), Personal Growth Initiative Scale - II (Robitschek et al., 2012) and Subjective Happiness Scale (Lyubomirsky \& Lepper, 1999). They also self-reported their demographics.

The TEIQue SF is a 30 item measure of the global trait emotional intelligence (trait EI). Some examples of items on the questionnaire include; "Expressing my emotions with words is not a problem for me", "I often find it difficult to adjust my life according to the circumstances" and "I'm usually able to find ways to control my emotions when I want to". A 7-point Likert response format was used and the total scores for the participants could range between 30 and 210 with 
higher scores indicating higher emotional intelligence. The reliability of scores from the TEIQue SF in the present study sample was 0.78 .

The PGIS consists of 16 items which measure the four sub-domains; Readiness for Change (4), Planfulness (5), Using Resources (3) and Intentional Behaviour (4). Items on the scale include: 'I set realistic goals for what I want to change about myself', 'I can tell when I am ready to make specific changes in myself', 'I know how to make a realistic plan in order to change myself' and 'I take every opportunity to grow as it comes up'. A total personal growth initiative score and subdomain scores were computed for all the participants in the study. In this study, an internal consistency value of 0.93 was obtained for scores from the PGIS overall scale.

The SHS comprised 4-items to measure an individual's subjective happiness in relation to others. Items on the scale include; 'In general, I consider myself...' with responses ranging between 1(not a very happy person) and 7(a very happy person), 'Some people are generally very happy. They enjoy life regardless of what is going on, getting the most out of everything. To what extent does this characterization describe you?' and responses ranged between 1(not at all) and 7(to a great deal). In this study, the scale showed a fair reliability with an internal consistency value of 0.65 .

\section{Procedure}

Permission for the study was granted by the department of psychology, University of Ghana. All ethical guidelines regarding the conduct of research involving human participants were strictly adhered to in this study. The students individually consented to participate in the study. The purpose of the study was explained to the students and those who agreed to partake in the study were administered the questionnaires in their various lecture halls. The students were informed 
that their participation in the study was voluntary and that their data were protected for use only for said research purpose.

\section{Data analysis}

Stepwise hierarchical regression analyses were used to predictive on subjective happiness from emotional intelligence and domains of personal growth initiative after adjusting for demographic characteristics. All the analysis were tested at two-tailed and $\mathrm{p}<.05$ was considered statistically significant. 


\section{RESULTS}

\section{Descriptive statistics}

Table 1 presents the descriptive statistics of the study variables.

Table 1. Pearson Correlation matrix showing the relationship among the study variables

\begin{tabular}{|c|c|c|c|c|c|c|c|c|c|c|c|c|c|c|}
\hline Variables & Mean & SD & 1 & 2 & 3 & 4 & 5 & 6 & 7 & 8 & 9 & 10 & 11 & 12 \\
\hline 1. Sex & 1.70 & .46 & $*$ & & & & & & & & & & & \\
\hline 2. Age & 21.72 & 3.61 & -.06 & $*$ & & & & & & & & & & \\
\hline 3. Marital Status & 1.96 & .20 & -.01 & $-.60^{* * *}$ & $*$ & & & & & & & & & \\
\hline 4. Religion & 1.08 & .35 & -.09 & .09 & .05 & $*$ & & & & & & & & \\
\hline 5. Level & 2.59 & 1.35 & .08 & $.51 * * *$ & -.08 & .11 & $*$ & & & & & & & \\
\hline 6. Emotional Intelligence & 151.72 & 20.14 & $.13^{*}$ & .00 & -.03 & .00 & .03 & $*$ & & & & & & \\
\hline 7. Personal Growth Initiative & 15.02 & 3.07 & -.01 & .12 & -.11 & -.04 & .08 & $.44 * * *$ & $*$ & & & & & \\
\hline 8. Readiness for Change & 15.22 & 3.35 & -.01 & .09 & -.04 & -.01 & .09 & $.34 * * *$ & $.87 * * *$ & $*$ & & & & \\
\hline 9. Planfulness & 18.85 & 4.36 & -.01 & .10 & -.10 & -.04 & .06 & $.43 * * *$ & $.93 * * *$ & $.78 * * *$ & $*$ & & & \\
\hline 10. Using Resources & 10.16 & 3.06 & .01 & .11 & -.10 & -.01 & .10 & $.29 * * *$ & $.76 * * *$ & $.51 * * *$ & $.60 * * *$ & $*$ & & \\
\hline 11. Intentional Behaviour & 15.86 & 3.36 & .01 & $.13^{*}$ & $-.13 *$ & -.06 & .03 & $.46 * * *$ & $.89 * * *$ & $.71 * * *$ & $.77 * * *$ & $.58 * * *$ & $*$ & \\
\hline 12. Subjective Happiness & 21.78 & 4.17 & .05 & $.16^{*}$ & $-.17 * *$ & .00 & .04 & $.51 * * *$ & $.29 * * *$ & $.20 * * *$ & $.25 * * *$ & $.19 * *$ & $.36 * * *$ & $*$ \\
\hline
\end{tabular}

$$
*=\mathrm{p}<.05, * *=\mathrm{p}<.01, * * *=\mathrm{p}<.001
$$


As can be observed from Table 1, age $(r=.16, p<.05)$ and marital status $(r=-.17, p<.01)$ were significantly correlated with participants overall subjective happiness. The level of emotional intelligence of the participants was significantly and positively correlated with their subjective happiness $(r=.51, p<.001)$. This suggests that the higher the participants' level of emotional intelligence, the happier they are with their lives. Overall personal growth initiative $(r=.29, p<$ $.001)$ as well as all the domains of personal growth initiative; Readiness for Change ( $r=.20, p<$ $.001)$, Planfulness $(r=.25, p<.001)$, Using Resources $(r=.19, p<.01)$ and Intentional Behaviour $(r=.36, p<.001)$ were significantly and positively correlated with participants' level of subjective happiness.

Predicting subjective happiness from emotional intelligence and personal growth initiative

Table 2 presents the results from sequential regression analysis of emotional intelligence and personal growth initiative as predictors of subjective happiness. 
Table 2. Influences of emotional intelligence and personal growth initiative on subjective wellbeing

\begin{tabular}{|c|c|c|c|c|c|c|c|}
\hline \multirow[t]{2}{*}{ Model } & \multirow[t]{2}{*}{ B } & \multirow[t]{2}{*}{ SEB } & \multirow[t]{2}{*}{$\beta$} & \multirow[t]{2}{*}{$\mathbf{t}$} & \multirow[t]{2}{*}{$\mathbf{p}$} & \multicolumn{2}{|c|}{ CI $(95 \%)$} \\
\hline & & & & & & Lower & Upper \\
\hline \multicolumn{8}{|l|}{ Step 1} \\
\hline Age & .09 & .09 & .08 & .99 & .32 & -.09 & .27 \\
\hline Marital Status & -3.05 & 1.68 & -.14 & -1.82 & .07 & -6.35 & -.26 \\
\hline$R^{2}$ & $.03 * *$ & & & & & & \\
\hline \multicolumn{8}{|l|}{ Step 2} \\
\hline Age & .11 & .08 & .10 & 1.39 & .17 & -.05 & .27 \\
\hline Marital Status & -1.89 & 1.46 & -.09 & -1.30 & .20 & -4.76 & .98 \\
\hline Emotional Intelligence & .10 & .01 & .45 & 7.29 & $.000 * * *$ & .07 & .12 \\
\hline Readiness for Change & -.03 & .11 & -.02 & -.27 & .79 & -.25 & .19 \\
\hline Planfulness & -.13 & .10 & -.14 & -1.35 & .18 & -.33 & .06 \\
\hline Using Resources & -.02 & .10 & -.01 & -.20 & .84 & -.21 & .17 \\
\hline Intentional Behaviour & .33 & .12 & .26 & 2.79 & $.01 * *$ & .10 & .56 \\
\hline$R^{2}$ & $.30 * * *$ & & & & & & \\
\hline$R^{2}$ change & $.27 * * *$ & & & & & & \\
\hline \multicolumn{8}{|c|}{$[F(2,241)=5.03, p<.01]$ for step 1 and $[F(7,236)=14.90, p<.001]$ for step 2} \\
\hline \multicolumn{8}{|c|}{ From the sequential regression analysis, demographic characteristics of the students explained 3\% } \\
\hline \multicolumn{8}{|c|}{ of variance in subjective happiness, $R^{2}=0.03, p<0.01$ (see Table 2). The introduction of the } \\
\hline \multicolumn{8}{|c|}{ emotional intelligence and personal growth initiative domains explained an added $27 \%$ (p. <.01). } \\
\hline \multicolumn{8}{|c|}{ Emotional intelligence was the strongest predictor of subjective happiness by accounting for $45 \%$} \\
\hline \multicolumn{8}{|c|}{ of the explained variance in subjective happiness while Intentional Behaviour accounted for $26 \%$} \\
\hline of the explained variance & subjectiv & lappines & Howe & & r chan & & \\
\hline & & & & & & & \\
\hline
\end{tabular}




\section{DISCUSSION AND CONCLUSION}

Results from this study showed that high levels of emotional intelligence are related with higher levels of subjective happiness and remain significant to subjective happiness status after other controlling for potential confounders such as age and marital status. This suggests that students self-reporting with emotional intelligence tend to be happier overall, compared to students selfreporting with less emotional intelligence. Several previous studies have reported the positive influence of emotional intelligence on the social wellbeing of students. For instance, higher emotional intelligence among young people is related to decreased depression (Extremera, Fernández-Berrocal, Ruiz-Aranda, \& Cabello, 2006; Salguero, Extremera, \& Fernández-Berrocal, 2012), subjective happiness, subjective well-being and life-satisfaction (Geng, 2016; Ruiz-Aranda et al., 2014), resilience and adaptive coping (Montes-Berges \& Augusto, 2007; Robitschek \& Keyes, 2009; Salovey et al., 2000; Schneider et al., 2013). Therefore, the finding of this study corroborate those of previous works which reported emotional intelligence important for social wellbeing among African students (Kim-Prieto \& Eid, 2004; Mpofu, 1999).

Happier students self-reported higher levels of personal growth initiative. This finding might be explained by the fact that personal growth initiative is related to one's priority goals (Cilliers \& Wissing, 1993; Oluyinka, 2011; Robitschek et al., 2012). Moreover, people with high personal growth initiative are more likely to adopt more adaptive coping strategies, psychological wellbeing, hope, experience lower self-discrepancies, and less psychological problems (Guse \& Vermaak, 2011; Mason, 2015; Wilson \& Somhlaba, 2016). After controlling for demographic characteristics and emotional intelligence, only intentional behaviour predicted increased subjective happiness. This lends credence to the assertion that happiness from African worldview 
is promoted by voluntary actions for social wellbeing of self and others (Ugwanyi, 2014). This finding suggests that students with optimism are also likely to engage in voluntary actions towards achieving happier lives (Delle Fave \& Soosai-Nathan, 2014; Mason, 2015; Wissing, 2014).

\section{Implications for Student Development Counselling}

Happy university students may be well adapted in their learner roles and social lives (Peltzer et al., 2017). It is essential for the counselling sections of universities to put in place programmes to help students deal with their emotions in their day-to-day interactions (Mason, 2015, 2017a, 2017b). Thus, academic institutions may accomplish much by attending to the emotional wellbeing of students for their positive psychological wellbeing. Students counselling services should seek to support intelligent emotional expression among students for happiness (Heizomi, Allahverdipour, Jafarabadi, \& Safaian, 2015), Moreover, it is also imperative for counselling services to increase students' sense of meaning and responsibility as these are related to goal-directed behaviour, which positively reflects in the ability to cope with stressors and better academic performance (Mason, 2017).

\section{Limitations of the study}

The sample for this study consisted of students from one public university in Ghana, hence caution should be exercised when generalising to the wider student population. In addition, since the data was cross-sectional in nature and with a younger age students population. Also the study did not account for temporal influences on students' subjective happiness. Future studies should apply longitudinal approaches to examine the trends and patterns of the influence of emotional intelligence and personal growth initiative over a period of time and varying by age of students. 


\section{Conclusion}

This study examined whether emotional intelligence and personal growth initiative among university students have any significant influence on their subjective happiness. Findings from the study showed that students' levels of emotional intelligence and personal growth initiative have significant positive impact on their subjective happiness which is an indicator of wellbeing. Therefore, it is important students are provided holistic guidance and counseling to enhance their ability to identity, manage and utilize their emotions. The findings also suggest that students' happiness is dependent on personal assets like emotional intelligence and personal growth initiative rather than material wellbeing alone. 


\section{REFERENCES}

Addai, I., Opoku-Agyeman, C., \& Amanfu, S. K. (2014). Exploring predictors of subjective well-being in Ghana: A micro-level study. Journal of Happiness Studies, 15(4), 869-890.

Addai, I., Opoku-Agyeman, C., \& Amanfu, S. K. (2015). Marriage and subjective well-being in Ghana. African Review of Economics and Finance, 7(1), 53-79.

Bar-On, R. (2005). The impact of emotional intelligence on subjective well-being: research article: general. Perspectives in Education, 23(1), 41-62.

Calys-Tagoe, B., Hewlett, S., Dako-Gyeke, P., Yawson, A., Bad-Doo, N., Seneadza, N., . . . Chatterji, S. (2014). Predictors of subjective well-being among older Ghanaians. Ghana Medical Journal, 48(4), 178-184.

Cilliers, F., \& Wissing, M. (1993). Sensitiewe relasievorming as bestuursdimensie: Die evaluering van'n ontwikkelingsprogram. SA Journal of Industrial Psychology, 19(1), 510.

Delle Fave, A., \& Soosai-Nathan, L. (2014). Meaning as inter-connectedness: theoretical perspectives and empirical evidence. Journal of Psychology in Africa, 24(1), 33-43.

Diener, E., Suh, E. M., \& Lucas, R. E. (1999). Subjective well-being: three decades of progress. Psychological Bulletin, 125(2), 276-302.

Extremera, N., Fernández-Berrocal, P., Ruiz-Aranda, D., \& Cabello, R. (2006). Inteligencia emocional, estilos de respuesta y depresión. Ansiedad y Estres, 12(2-3), 191-205.

Furnham, A., \& Petrides, K. (2003). Trait emotional intelligence and happiness. Social Behavior and Personality: an international journal, 31(8), 815-823.

Gallagher, E. N., \& Vella-Brodrick, D. A. (2008). Social support and emotional intelligence as predictors of subjective well-being. Personality and individual differences, 44(7), 15511561.

Garland, E. L., Fredrickson, B., Kring, A. M., Johnson, D. P., Meyer, P. S., \& Penn, D. L. (2010). Upward spirals of positive emotions counter downward spirals of negativity: Insights from the broaden-and-build theory and affective neuroscience on the treatment of emotion dysfunctions and deficits in psychopathology. Clinical Psychology Review, 30(7), 849-864.

Geng, Y. (2016). Gratitude mediates the effect of emotional intelligence on subjective wellbeing: A structural equation modeling analysis. Journal of Health Psychology, 1359105316677295.

George, L. K. (2009). Still happy after all these years: Research frontiers on subjective wellbeing in later life. Journals of Gerontology Series B: Psychological Sciences and Social Sciences, 65(3), 331-339.

Guse, T., \& Vermaak, Y. (2011). Hope, psychosocial well-being and socioeconomic status among a group of South African adolescents. Journal of Psychology in Africa, 21(4), 527-533.

Guse, T., Vescovelli, F., \& Croxford, S.-A. (2017). Subjective Well-Being and Gratitude Among South African Adolescents: Exploring Gender and Cultural Differences. Youth \& Society, $0044118 X 17697237$.

Heizomi, H., Allahverdipour, H., Jafarabadi, M. A., \& Safaian, A. (2015). Happiness and its relation to psychological well-being of adolescents. Asian journal of psychiatry, 16, 5560. 
Kim-Prieto, C., \& Eid, M. (2004). Norms for experiencing emotions. Journal of Happiness Studies, 5(3), 241-268.

Larsen, R. J. (2000). Toward a science of mood regulation. Psychological Inquiry, 11(3), 129141.

Lyubomirsky, S., \& Lepper, H. S. (1999). A measure of subjective happiness: Preliminary reliability and construct validation. Social Indicators Research, 46(2), 137-155.

Martins, A., Ramalho, N., \& Morin, E. (2010). A comprehensive meta-analysis of the relationship between emotional intelligence and health. Personality and individual differences, 49(6), 554-564.

Mason, H. D. (2015). Meaning, happiness and psychological distress: correlates and qualitative reflections. Journal of Psychology in Africa, 25(1), 15-19.

Mason, H. D. (2017a). Meaning as a coping resource: Experiences of nursing students. Journal of Psychology in Africa, 27(1), 74-79.

Mason, H. D. (2017b). Sense of meaning and academic performance: A brief report. Journal of Psychology in Africa, 27(3), 282-285.

Montes-Berges, B., \& Augusto, J. M. (2007). Exploring the relationship between perceived emotional intelligence, coping, social support and mental health in nursing students. Journal of Psychiatric and Mental Health Nursing, 14(2), 163-171.

Mpofu, E. (1999). Modernity and subjective well-being in Zimbabwean college students. South African Journal of Psychology, 29(4), 191-200.

Mpofu, E. (2011). Counseling people of African ancestry: Cambridge University Press.

Neff, K. D., Rude, S. S., \& Kirkpatrick, K. L. (2007). An examination of self-compassion in relation to positive psychological functioning and personality traits. Journal of Research in Personality, 41(4), 908-916.

Ngamaba, K. H. (2016). Happiness and life satisfaction in Rwanda. Journal of Psychology in Africa, 26(5), 407-414.

Oluyinka, O. (2011). Psychological predictors of attitude towards seeking professional psychological help in a Nigerian university student population. South African Journal of Psychology, 41(3), 310-327.

Osei-Tutu, A., Dzokoto, V. A., Hanke, K., Adams, G., \& Belgrave, F. Z. (2018). Conceptions of love in Ghana: An exploration among Ghanaian Christians. Journal of Psychology in Africa, 28(2), 83-88.

Peltzer, K., \& Pengpid, S. (2017). Dietary consumption and happiness and depression among university students: A cross-national survey. Journal of Psychology in Africa, 27(4), 372377.

Peltzer, K., Pengpid, S., Sodi, T., \& Mantilla Toloza, S. C. (2017). Happiness and health behaviours among university students from 24 low, middle and high income countries. Journal of Psychology in Africa, 27(1), 61-68.

Petrides, K., \& Furnham, A. (2006). The role of trait emotional intelligence in a gender-specific model of organizational variables. Journal of Applied Social Psychology, 36(2), 552-569.

Robitschek, C. (1998). Personal growth initiative: The construct and its measure. Measurement and Evaluation in Counseling and Development, 30(4), 183.

Robitschek, C., Ashton, M. W., Spering, C. C., Geiger, N., Byers, D., Schotts, G. C., \& Thoen, M. A. (2012). Development and Psychometric Evaluation of the Personal Growth Initiative Scale-II. Journal of Counseling Psychology, 59(2), 274-287. 
Robitschek, C., \& Cook, S. W. (1999). The influence of personal growth initiative and coping styles on career exploration and vocational identity. Journal of Vocational Behavior, 54(1), 127-141.

Robitschek, C., \& Keyes, C. L. (2009). Keyes's model of mental health with personal growth initiative as a parsimonious predictor. Journal of Counseling Psychology, 56(2), 321.

Rugira, J., Nienaber, A. W., \& Wissing, M. P. (2013). Psychological well-being among Tanzanian university students. Journal of Psychology in Africa, 23(3), 425-429.

Ruiz-Aranda, D., Extremera, N., \& Pineda-Galán, C. (2014). Emotional intelligence, life satisfaction and subjective happiness in female student health professionals: the mediating effect of perceived stress. Journal of Psychiatric and Mental Health Nursing, 21(2), 106-113.

Salguero, J. M., Extremera, N., \& Fernández-Berrocal, P. (2012). Emotional intelligence and depression: The moderator role of gender. Personality and Individual Differences, 53(1), 29-32.

Salovey, P., \& Mayer, J. D. (1990). Emotional intelligence. Imagination, Cognition and Personality, 9(3), 185-211.

Salovey, P., Rothman, A. J., Detweiler, J. B., \& Steward, W. T. (2000). Emotional states and physical health. American Psychologist, 55(1), 110.

Schneider, T. R., Lyons, J. B., \& Khazon, S. (2013). Emotional intelligence and resilience. Personality and Individual Differences, 55(8), 909-914.

Shorey, H. S., Little, T. D., Snyder, C., Kluck, B., \& Robitschek, C. (2007). Hope and personal growth initiative: A comparison of positive, future-oriented constructs. Personality and Individual Differences, 43(7), 1917-1926.

Stevic, C. R., \& Ward, R. M. (2008). Initiating personal growth: The role of recognition and life satisfaction on the development of college students. Social Indicators Research, 89(3), 523.

Sulemana, I. (2015). An empirical investigation of the relationship between social capital and subjective well-being in Ghana. Journal of Happiness Studies, 16(5), 1299-1321.

Tsai, M. C., \& Dzorgbo, D. B. S. (2012). Familial Reciprocity and Subjective Well-being in Ghana. Journal of Marriage and Family, 74(1), 215-228.

Ugwuanyi, L. O. (2014). The question of happiness in African philosophy. South African Journal of Philosophy, 33(4), 513-522.

Wilson, A., \& Somhlaba, N. Z. (2016). Psychological well-being in a context of adversity: Ghanaian adolescents' experiences of hope and life satisfaction. Africa Today, 63(1), 84103.

Wissing, M. P. (2014). Meaning and relational well-being: a reflection on the state of the art and a way forward. Journal of Psychology in Africa, 24(1), 115-121.

Ye, J., Yeung, D. Y., Liu, E. S., \& Rochelle, T. L. (2018). Sequential mediating effects of provided and received social support on trait emotional intelligence and subjective happiness: A longitudinal examination in Hong Kong Chinese university students. International Journal of Psychology, DOI: 10.1002/ijop.12484.

Zeidner, M., Matthews, G., \& Roberts, R. D. (2012). The Emotional Intelligence, Health, and Well-Being Nexus: What Have We Learned and What Have We Missed? Applied Psychology: Health and Well-Being, 4(1), 1-30. 